\title{
Assessing the effectiveness of Chagas disease education for healthcare providers in the United States
}

\author{
Paula Stigler Granados ${ }^{*} \mathbb{D}$, Gerardo J. Pacheco, Evangelina Núñez Patlán, Jose Betancourt and Lawrence Fulton
}

\begin{abstract}
Background: Chagas disease is a zoonotic infection caused by the parasite Trypanosoma cruzi, which affects an estimated 8-11 million people globally. Chagas disease is almost always associated with poverty in rural areas and disproportionately impacts immigrants from Latin America living in the United States. Approximately 20-30\% of people who are infected with Chagas disease will develop a chronic form of the infection that can be fatal if left untreated. Chagas disease is vastly underestimated in the United States, often goes undiagnosed and is not well understood by most U.S. healthcare providers. One of the most important ways at reducing barriers to improving diagnostics of Chagas disease in the U.S. is giving healthcare providers the most up-to-date information and access to leading experts.

Methods: An online webinar was conducted for healthcare providers, veterinarians and public health professionals using Chagas disease expert panelists. Pre and post tests were administered to participants $(n=57)$ to determine the efficacy in raising awareness and to determine key focus areas for improving knowledge. A Wilcoxon rank-sum was used for non-parametric variables equivalent and for questions that assessed knowledge the McNemar's ChiSquare test was used.
\end{abstract}

Results: There were statistically significant learning increases in multiple categories including transmission $(p=<.001)$, clinical presentation ( $p=0.016)$, diagnostics $(p=<.001)$, and treatment $(p=<.001)$.

Conclusion: Providing easily accessible learning opportunities using validated testing and evaluations should be further developed for rural healthcare providers in the U.S. as well as healthcare providers serving under represented populations such as immigrants. There is a clear lack of knowledge and awareness surrounding Chagas disease in the United States and just by raising awareness and providing education on the topic, lives will be saved.

Keywords: Chagas disease, Neglected tropical diseases, Trypanosoma cruzi, Online medical education, Telehealth

\section{Background}

Chagas disease is a zoonotic infection caused by the parasite Trypanosoma cruzi (T.cruzi), which affects an estimated 8-11 million people globally [1-8]. Approximately $20-30 \%$ of people who are infected with Chagas disease will develop a chronic form of the infection that

\footnotetext{
* Correspondence: psgranados@txstate.edu

School of Health Administration, Texas State University, 601 University Dr, San Marcos, TX 78666-4606, USA
}

can lead to fatal heart or gastrointestinal diseases $[5,9$, 10]. Although Chagas disease is most commonly found in Latin American countries, there has been a growing concern that it is vastly underestimated in the United States $[1-5,9,11]$ Estimates that use modeled data suggest that there are between 326,000 and 347,000 individuals born in Latin America living in the United States that are infected with T.cruzi $[2,3,12]$. This population may hold the highest burden of Chagas disease in the

(c) The Author(s). 2020 Open Access This article is licensed under a Creative Commons Attribution 4.0 International License, which permits use, sharing, adaptation, distribution and reproduction in any medium or format, as long as you give appropriate credit to the original author(s) and the source, provide a link to the Creative Commons licence, and indicate if changes were made. The images or other third party material in this article are included in the article's Creative Commons licence, unless indicated otherwise in a credit line to the material. If material is not included in the article's Creative Commons licence and your intended use is not permitted by statutory regulation or exceeds the permitted use, you will need to obtain permission directly from the copyright holder. To view a copy of this licence, visit http://creativecommons.org/licenses/by/4.0/ The Creative Commons Public Domain Dedication waiver (http://creativecommons.org/publicdomain/zero/1.0/) applies to the data made available in this article, unless otherwise stated in a credit line to the data. 
United States due to a higher prevalence in their countries of origin $[13,14]$. However, in the southern United States there have been an increasing number of autochthonous and congenital transmission cases being reported since 2000 [3, 15-19]. It is generally believed that transmission rates in the United States are lower than in Latin America, mainly because of housing conditions and different vector behaviors $[16,20]$. Nevertheless, there are 29 out of 50 states reporting triatomine insects with 10 of the 11 species found to have the ability to be infected with the parasite $[15,21,22]$. In several studies of triatomines collected in Texas, more than $60 \%$ were infected with T. cruzi and of those infected many had human blood in their gut [22-26]. Many of these studies suggest that locally acquired infections in the United States may occur more frequently than previously thought, however due to a lack of knowledge about Chagas disease in the United States it is often overlooked [18, 27].

Regardless of where a person is infected, less than $1 \%$ of people in the United States will ever receive a clinical diagnosis of Chagas disease and even fewer will ever receive treatment $[4,12]$. This lack of diagnosis and treatment is a result of a combination of factors including an absence of awareness by healthcare providers, limited diagnostic tools, and access to healthcare by the populations most vulnerable to this disease $[12,28,29]$. According to Lynn, et al., they found that shared risk factors for transmission of Chagas disease in the United States were living in a rural area and/or a history of outdoor activities or work [15]. This leads us to conclude that healthcare providers serving populations in rural areas or underserved migrant population are a good starting point to target Chagas disease education efforts [12, 29-31].

As of 2017, only six states participate in surveillance and reporting of Chagas disease [12, 31, 32]. Educational materials on Chagas disease may be found online by several different sources and from the individual state health departments and the Centers for Disease Control and Prevention (CDC). Despite the availability of educational materials, a study on patient perspectives and access to Chagas disease in the United States emphasizes low awareness among providers and nonexistent health education campaigns as barriers to treatment [29]. In 2015, the CDC funded several projects to raise awareness and improve knowledge of Chagas disease among healthcare providers in the United States. As a result, the Texas Chagas Taskforce (TCTF) was developed and focused on using a One Health approach to information dissemination [25, 33]. The TCTF recognized the need for a structured education program and therefore developed an online webinar on Chagas disease targeting healthcare providers, veterinarians and public health professionals. The purpose of this paper is to analyze the efficacy of an online education program for health professionals in raising awareness of Chagas disease and to determine key focus areas for improving knowledge on this complex disease.

\section{Methods}

A voluntary group of individuals from healthcare and veterinary medicine backgrounds participated in a $2-\mathrm{h}$ online webinar about Chagas disease. Of the participants, $n=57$ completed both the pre and post-test knowledge assessment (see Appendix 1 and 2). The session was conducted online during the afternoon and consisted of six individual presentations by Chagas disease experts, including: physicians, veterinarians and epidemiologists at the state and national levels. The presentations were followed by time for questions and answers from participants. The targeted subjects for study recruitment were healthcare providers, veterinarians and public health professionals, most of whom were practicing in Texas. A promotional flyer was distributed via emails and social media and university list serves. An online event registration site was used to register participants and an informed consent notice was included in the pre-knowledge test, which participants were asked to agree or disagree with before proceeding with the study. This study was reviewed and approved by the UTHealth Institutional Review Board.

Qualtrics software [34] was chosen as the survey tool to host the pre- and post-knowledge tests as well as the evaluation of training. WebEx software was utilized as the host teleconferencing platform. After registration, participants received an email with the Qualtrics link to a pre-knowledge test and the link to the online webinar. Email reminders with the link were sent to the participants one week and again one day prior to the training session. The pre-knowledge test consisted of 16 questions (12 knowledge and 4 demographic) and was to be completed prior to the session. The post-knowledge test was the same as the pre-knowledge test with the same 12 knowledge questions. Both the pre and post knowledge questions were developed and piloted with Chagas disease experts from the TCTF and based on information provided in an online course from the Centers for Disease Control and Prevention [35]. An evaluation of the training survey given upon completion of the webinar was given and consisted of 20 questions addressing occupation, program experience, and program content. Both the post-knowledge test and the evaluation were to be completed after the last session. A total of 239 participants registered for the sessions; however, only 146 participated in the webinar and of those only 57 completed both the pre and post tests. Continuing education credit was given to those participants that attended and 
completed both tests. There were 159 continuing education credits provided (51 CMEs and 104 CEUs).

Two different statistical tests evaluated the efficacy of the educational event. For self-reported knowledge gains (e.g., how would you describe your knowledge of Chagas disease and how confident are you that your knowledge is up to date), Wilcoxon rank-sum tests were used. A Wilcoxon rank-sum was used as a non-parametric equivalent to the paired t-test, which was appropriate as the data were not quantitative. For questions that assessed actual knowledge, McNemar's Chi-Square test was used. This test was deemed appropriate to evaluate correct / incorrect responses before and after session. The analytical software for the study was R Statistical Software [36] and Microsoft.

\section{Results}

Of the146 attendees, 25\% were doctors of veterinary medicine, $12 \%$ medical doctors or doctors of osteopathy, $10 \%$ nurses, and $54 \%$ were other healthcare or public health professionals. Of those completing both the preand post-tests, $25 \%$ were doctors of veterinary medicine, $14.3 \%$ were medical doctors or doctors of osteopathy, $8.9 \%$ were nurses, and the remaining $51.8 \%$ were other healthcare or public health professionals. Table 1 provides the means and standard deviations for each of the questions (truncated item) on the knowledge assessment. The table provides 1 ) the results for the pre- and posttests, 2) the difference between the two tests, and 3) a 95\% confidence interval for the difference.

Starting at item 3 in Table 1 ("Present in Texas?"), the values are associated with correct or incorrect answers and may be interpreted as percentages. Prior to the training, 96\% were correct in understanding that the disease was present in Texas, and $84 \%$ knew that the disease was caused by a parasite rather than a virus, bacterium, or other. Only 30\% knew that T. cruzi, the parasite that causes Chagas disease was not transmitted by the saliva of an infected triatome (but rather the feces). While $73 \%$ knew that Chagas disease was prevalent in the Southern United States, only 39\% could identify that $21-40 \%$ of those infected develop clinical disease. Eighty percent knew the symptoms prior to training, and $73 \%$ identified the clinical manifestations with only $41 \%$ correctly identifying the laboratory methods used to diagnose Chagas disease. Fifty-two percent knew the treatment recommendations, and only 38\% understood EKG findings associated with Chagas disease.

Figure 1 graphs the post-test less the pre-test mean scores. From this figure, it is clear that there were knowledge improvements for all questions except for one: True or False: Chagas disease is present in Texas.

A Wilcoxon rank sum test of self-assessed Chagas disease knowledge ("How would you describe your level of knowledge about Chagas disease?") indicated a significant difference in pre-test versus post-test $(\mathrm{V}=35$, $p<.001)$. Self-assessed Chagas disease knowledge improved from a median of 3 to a median of 4 . Another Wilcoxon rank sum test evaluated "How confident are you that your knowledge on Chagas disease is up to date?" Again, the results were statistically significant $(\mathrm{V}=39, p<.001)$.

Table 1 Chagas disease (CD) knowledge pretest, posttest with difference means / standard deviations by survey question

\begin{tabular}{|c|c|c|c|c|c|c|c|c|}
\hline Item $(n=56)$ & $\begin{array}{l}\text { Pre } \\
\text { Mean }\end{array}$ & $\begin{array}{l}\text { Post } \\
\text { Mean }\end{array}$ & $\begin{array}{l}\text { Pre-Post } \\
\text { Mean }\end{array}$ & $\begin{array}{l}\text { Pre } \\
\text { SD }\end{array}$ & $\begin{array}{l}\text { Post } \\
\text { SD }\end{array}$ & $\begin{array}{l}\text { Pre-Post } \\
\text { SD }\end{array}$ & $\begin{array}{l}\text { Lower } 95 \% \\
\text { Post-Pre }\end{array}$ & $\begin{array}{l}\text { Upper } 95 \% \\
\text { Post-Pre }\end{array}$ \\
\hline $\begin{array}{l}\text { Describe your level of CD Knowledge } \\
1 \text { (I don't know anything); } 2 \text { (Very limited); } 3 \text { (Limited); } \\
4 \text { (Good); } 5 \text { (Excellent) }\end{array}$ & 3.13 & 3.95 & 0.82 & 0.95 & 0.82 & 0.79 & 0.61 & 1.03 \\
\hline $\begin{array}{l}\text { How confident are you with your CD Knowledge is current? } \\
1 \text { (Don't know); } 2 \text { (Not at all confident); } 3 \text { (Somewhat confident); } \\
4 \text { (Confident); } 5 \text { (Very confident) }\end{array}$ & 2.84 & 3.96 & 1.13 & 1.01 & 0.93 & 1.08 & 0.84 & 1.41 \\
\hline CD is present in Texas? (True or False) & 0.96 & 0.96 & 0.00 & 0.19 & 0.19 & 0.30 & -0.08 & 0.08 \\
\hline Cause of CD & 0.84 & 0.91 & 0.07 & 0.37 & 0.29 & 0.26 & 0.00 & 0.14 \\
\hline Transmission of CD & 0.30 & 0.59 & 0.29 & 0.46 & 0.50 & 0.49 & 0.16 & 0.42 \\
\hline What part of the world is CD transmitted? & 0.73 & 0.91 & 0.18 & 0.45 & 0.29 & 0.39 & 0.08 & 0.28 \\
\hline What $\%$ of patients develop clinical disease? & 0.39 & 0.70 & 0.30 & 0.49 & 0.46 & 0.54 & 0.16 & 0.44 \\
\hline CD Symptoms & 0.80 & 0.88 & 0.07 & 0.40 & 0.33 & 0.37 & -0.03 & 0.17 \\
\hline CD Clinical Manifestations & 0.73 & 0.89 & 0.16 & 0.45 & 0.31 & 0.42 & 0.05 & 0.27 \\
\hline Methods to diagnose CD & 0.41 & 0.86 & 0.45 & 0.50 & 0.35 & 0.54 & 0.31 & 0.59 \\
\hline CD Treatment & 0.52 & 0.77 & 0.25 & 0.50 & 0.43 & 0.44 & 0.14 & 0.36 \\
\hline EKG Typical of CD & 0.38 & 0.48 & 0.11 & 0.49 & 0.50 & 0.56 & -0.04 & 0.25 \\
\hline
\end{tabular}




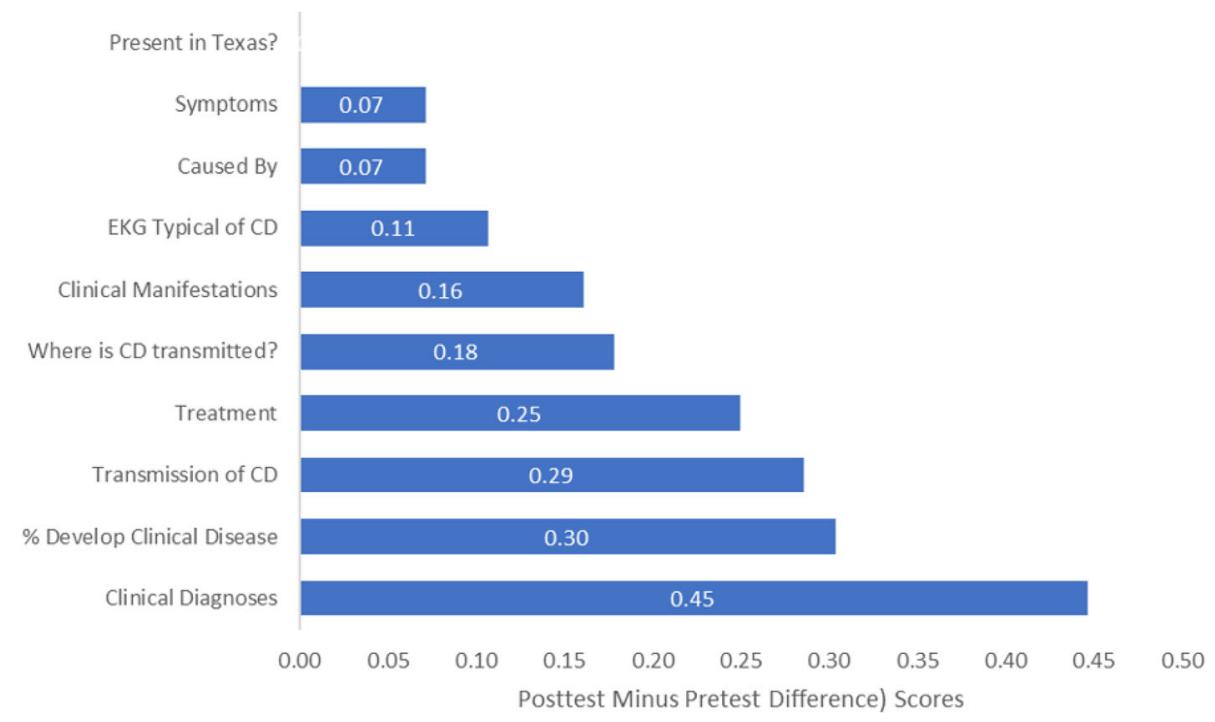

Fig. 1 Graph of the Chagas disease knowledge post-test less the pre-test scores

McNemar Chi-Square tests were run for each of the knowledge questions in the survey. Table 2 provides the results. Pre-post statistically significant differences were found in 6 of the 10 questions including questions about how Chagas disease is transmitted $(p<.001)$, where it is transmitted via vectors $(p<.005)$ what percentage of infected individuals develop clinical disease $(\mathrm{p}<.001)$, what clinical manifestations occur $(p=.016)$, laboratory methods of how Chagas disease is diagnosed $(p<.001)$, and how Chagas disease is treated $(\mathrm{p}<.001)$. Of the 56 attendees, $96 \%$ knew in advance that Chagas disease was present in Texas, and that remained static after training. There were increases in knowledge for all other survey questions, even for those questions that were not statistically significant. Table 1 shows the post-pre-test mean differences.

Table 2 Chagas disease pre-post knowledge analysis of questions in survey

\begin{tabular}{lll}
\hline Question & ${\text { McNemar } \mathbf{~}^{\mathbf{2}}}_{\mathbf{1}}$ & $\boldsymbol{p}$-value \\
\hline Present in Texas? & 0.000 & 1.000 \\
Cause of CD & 2.250 & 0.134 \\
Transmission of CD & 12.500 & $<.001^{*}$ \\
Where is CD transmitted? & 8.100 & $<.005^{*}$ \\
\% Develop Clinical Disease & 12.190 & $<.001^{*}$ \\
Symptoms & 1.125 & 0.289 \\
Clinical Manifestations & 5.818 & $0.016^{*}$ \\
Methods to diagnose CD & 21.333 & $<.001^{*}$ \\
Treatment & 12.071 & $<.001^{*}$ \\
EKG Typical of CD & 1.388 & 0.239 \\
\hline
\end{tabular}

*Statistically significant at a value of $<.05$

\section{Discussion}

The value and acceptability of webinar platforms to deliver training to groups is well-documented, often with good learning outcomes [37-43]. As the technology and tools that facilitate delivery of training through this evolving medium continue to mature, those seeking to raise awareness of emerging health threats such as Chagas disease recognize the invaluable worth of embracing this technology and assessment of learning [44]. The results of the pre- and post-test evaluations in this study indicate an increase in overall knowledge of Chagas disease among the healthcare professionals who participated in the webinar. Prior research highlights the relatively low number of studies that evaluate the awareness of Chagas disease among healthcare professionals, particularly those working with migrants from Latin America or who are physically located in Chagasendemic areas [44]. These studies are critical in assessing the knowledge, skills, and abilities of healthcare providers to recognize and identify this hidden but growing threat, correctly diagnose it and offer proper treatment. As with any disease or health condition that burdens a population, the crucial first step in addressing it is correctly recognizing and identifying its presence. The results of the pre-test indicate that while most of those who took the pre-test understood that Chagas disease is found in Texas, the extent of their knowledge of Chagas disease beyond this fact was minimal, particularly the poor, initial score on the 'clinical diagnosis' question. This is particularly concerning for those providers who encounter a patient with potential signs and symptoms of exposure to the bite of an infected triatomine insect or have a high-risk patient and 
may elect to dismiss the real possibility of a Chagas disease diagnosis.

Raising the awareness of healthcare providers and professional in other areas such as veterinary medicine and public health of the presence of Chagas disease in what has historically been considered nonendemic regions will aid them in asking the right questions of their patients/clients/populations. Additionally, the pre-test answers to the questions 'transmission of Chagas disease' and 'percent development of Chagas disease' indicate an insufficient preparedness of the provider to inform and educate their patient on what to look for in their homes or work places to see if they may have elevated risks of exposure to the vector.

Limitation(s): Although a total of 240 participants registered for and attended the sessions, the actual number of participants who completed both the pre and post-test knowledge assessment was 57 . This relatively small sample size may not be representative of the population and study findings may not be representative of the population. Additionally, the study may be subject to self-selection bias as those who responded to the offer of participating in the training, and who successfully completed it may illustrate a higher level of interest in Chagas disease over the population of providers in general. Unlike other infectious diseases, no validated tool existed at the time of this webinar to assess healthcare providers' knowledge on Chagas disease. Therefore, the questionnaire used was not a comprehensive tool and mainly focused on providers in Texas.

\section{Conclusion}

These findings illustrate the need to educate healthcare providers and other public health professionals on Chagas disease, as it is a complex disease that is not well understood in the United States. Increasing awareness, especially among those providers in rural areas and serving populations such as recent immigrants is a high priority. However, face-to-face educational opportunities for this group of professionals may not be possible or could be cost-prohibitive. The webinar demonstrated significant knowledge increases in several areas and proved to be effective in disseminating information from experts on the subject. We recommend that future planning for continued educational online platforms and programs be continued and improve the target audiences. Incorporating public health / community health workers into these trainings could also help make an impact on 'arming' populations at risk with the knowledge and tools to better protect themselves against this silent threat.

\section{Supplementary information}

Supplementary information accompanies this paper at https://doi.org/10. 1186/s12879-020-05474-W.

\section{Additional file 1}

Additional file 2.

\section{Abbreviations \\ T.cruzi: Trypanosoma cruzi; CDC: Centers for Disease Control and Prevention; TCTF: Texas Chagas Taskforce; CD: Chagas disease}

\section{Acknowledgements}

The authors would like to acknowledge Dr. Susan Montgomery with the Centers for Disease Control for her guidance in developing the webinars and its contents.

\section{Authors' contributions}

PSG contributed to the research development and writing; LF analyzed and interpreted the data, GP assisted with data collection and writing; ENP contributed to writing and review; JB contributed to writing, research and review. All authors read and approved the final manuscript.

\section{Funding}

The webinar was supported by the Cooperative Agreement Number, 1U2GGH001640-01, funded by the Centers for Disease Control and Prevention. The funding was only used in support of the efforts of the webinar and not for the completing of this paper. The contents of this paper are solely the responsibility of the authors and do not necessarily represent the official views of the Centers for Disease Control and Prevention or the Department of Health and Human Services.

\section{Availability of data and materials}

The datasets used and/or analyzed during the current study are available from the corresponding author on reasonable request.

\section{Ethics approval and consent to participate}

This study was reviewed and approved by the UTHealth School of Public Health Institutional Review Board. All participants were provided a written consent at the beginning of the online survey and were required to check the box marked "accept" before being given the online survey.

Consent for publication

Not applicable.

\section{Competing interests}

The authors declare that they have no competing interests.

Received: 15 July 2020 Accepted: 5 October 2020

Published online: 09 October 2020

\section{References}

1. Bern C, Kjos S, Yabsley MJ, Montgomery SP. Trypanosoma cruzi and Chagas' disease in the United States. Clin Microbiol Rev. 2011;24(4):655-81.

2. Bern C, Montgomery SP. An estimate of the burden of Chagas disease in the United States. Clin Infect Dis. 2009;49(5):e52-e4.

3. Manne-Goehler J, Umeh CA, Montgomery SP, Wirtz VJ. Estimating the burden of Chagas disease in the United States. PLoS Neglect Trop Dis. 2016; 10(11).

4. Manne-Goehler J, Reich MR, Wirtz VJ. Access to care for Chagas disease in the United States: a health systems analysis. Am J Trop Med Hygiene. 2015; 93(1):108-13.

5. Montgomery SP, Starr MC, Cantey PT, Edwards MS, Meymandi SK Neglected parasitic infections in the United States: Chagas disease. Am J Trop Med Hygiene. 2014;90(5):814-8.

6. Lee BY, Bacon KM, Bottazzi ME, Hotez PJ. Global economic burden of Chagas disease: a computational simulation model. Lancet Infect Dis. 2013; 13(4):342-8.

7. Schmunis GA, Yadon ZE. Chagas disease: a Latin American health problem becoming a world health problem. Acta Trop. 2010;115(1-2):14-21. 
8. Rassi A Jr, Rassi A, Marcondes de Rezende J. American trypanosomiasis (Chagas disease). Infect Dis Clin N Am. 2012;26(2):275-91.

9. Bern C, Montgomery SP, Herwaldt BL, Rassi A, Marin-Neto JA, Dantas RO, et al. Evaluation and treatment of Chagas disease in the United States: systematic review. Jama. 2007;298(18):2171-81.

10. Marin-Neto JA, Simões MV, Sarabanda ÁVL. Chagas' heart disease. Arq Bras Cardiol. 1999;72(3):247-80.

11. Manne JM, Snively CS, Ramsey JM, Salgado MO, Bärnighausen T, Reich MR. Barriers to treatment access for Chagas disease in Mexico. PLoS Negl Trop Dis. 2013;7(10):e2488.

12. Forsyth CJ, Granados PS, Pacheco GJ, Betancourt JA, Meymandi SK. Current gaps and needs for increasing access to healthcare for people with Chagas disease in the USA. Curr Trop Med Rep. 2019;6(1):13-22.

13. Moncayo Á, Silveira AC. Current epidemiological trends of Chagas disease in Latin America and future challenges: Epidemiology, surveillance, and health policies. American Trypanosomiasis Chagas Disease: Elsevier; 2017. p. 59-88.

14. Meymandi SK, Forsyth CJ, Soverow J, Hernandez S, Sanchez D, Montgomery $\mathrm{SP}$, et al. Prevalence of Chagas disease in the Latin American-born population of Los Angeles. Clin Infect Dis. 2017:64(9):1182-8.

15. Lynn MK, Bossak BH, Sandifer PA, Watson A, Nolan MS. Contemporary autochthonous human Chagas disease in the USA. Acta Trop. 2020;205: 105361

16. Klotz SA, Dorn PL, Mosbacher M, Schmidt JO. Kissing bugs in the United States: risk for vector-borne disease in humans. Environmental health insights. 2014;8:EHI.S16003.

17. Cantey PT, Stramer SL, Townsend RL, et al. The United States trypanosoma cruzi infection study: evidence for vector-borne transmission of the parasite that causes chagas disease among United States blood donors: transfusion; 2012.

18. Garcia MN, Aguilar D, Gorchakov R, et al. Evidence of autochthonous chagas disease in southeastern Texas: am J trop med Hyg; 2015.

19. Hernandez S, Flores CA, Viana GM, Sanchez DR, Traina MI, Meymandi SK Autochthonous transmission of Trypanosoma cruzi in southern California. Open forum infectious diseases. Oxford University Press; 2016. https://doi. org/10.1093/ofid/ofw227

20. Klotz SA, Dorn PL, Klotz JH, Pinnas JL, Weirauch C, Kurtz JR, et al. Feeding behavior of triatomines from the southwestern United States: an update on potential risk for transmission of Chagas disease. Acta Trop. 2009:111(2):114-8.

21. Eggers P. Notes from the field: identification of a Triatoma sanguisuga "kissing bug"-Delaware, 2018. MMWR Morb Mortal Wkly Rep. 2019; 6868(15):359.

22. Curtis-Robles R, Auckland LD, Snowden KF, Hamer GL, Hamer SA. Analysis of over 1500 triatomine vectors from across the US, predominantly Texas, for Trypanosoma cruzi infection and discrete typing units. Infect Genet Evol. 2018:58:171-80.

23. Gorchakov R, Trosclair LP, Wozniak EJ, Feria PT, Garcia MN, Gunter SM, et al. Trypanosoma cruzi infection prevalence and bloodmeal analysis in triatomine vectors of Chagas disease from rural peridomestic locations in Texas, 2013-2014. J Med Entomol. 2016:53(4):911-8.

24. Wozniak EJ, Lawrence G, Gorchakov R, Alamgir H, Dotson E, Sissel B, et al. The biology of the triatomine bugs native to south Central Texas and assessment of the risk they pose for autochthonous Chagas disease exposure. J Parasitol. 2015:101(5):520-8.

25. Garcia MN, O'Day S, Fisher-Hoch S, Gorchakov R, Patino R, Arroyo TPF, et al. One health interactions of Chagas disease vectors, canid hosts, and human residents along the Texas-Mexico border. PLoS Neglected Trop Dis. 2016; 10(11):e0005074.

26. Gunter SM, Murray KO, Gorchakov R, Beddard R, Rossmann SN, Montgomery $\mathrm{SP}$, et al. Likely autochthonous transmission of Trypanosoma cruzi to humans, south Central Texas, USA. Emerg Infect Dis. 2017;23(3):500-3.

27. Garcia M, Woc-Colburn L, Rossmann S, Townsend R, Stramer S, Bravo M, et al. Trypanosoma cruzi screening in Texas blood donors, 2008-2012. Epidemiol Infect. 2016;144(5):1010-3.

28. Bern C, Messenger LA, Whitman JD, Maguire JH. Chagas disease in the United States: a public health approach. Clin Microbiol Rev. 2019;33(1): e00023-19.

29. Forsyth CJ, Hernandez S, Flores CA, Roman MF, Nieto JM, Marquez G, et al. "It's like a phantom disease": patient perspectives on access to treatment for Chagas disease in the United States. Am J Trop Med Hygiene. 2018;98(3):735-41.

30. Tan MT, Matthews KR. Misconceptions and limited awareness of Chagas disease in Texas among surveyed Houston physicians; 2018.
31. Forsyth C, Meymandi S, Moss I, Cone J, Cohen R, Batista C. Proposed multidimensional framework for understanding Chagas disease healthcare barriers in the United States. PLoS Neglect Trop Dis. 2019;13(9):e0007447.

32. Bennett C, Straily A, Haselow D, Weinstein S, Taffner R, Yaglom H, et al. Chagas disease surveillance activities_-seven states, 2017. Morb Mortal Wkly Rep. 2018;67(26):738.

33. Curtis-Robles R, Wozniak EJ, Auckland LD, Hamer GL, Hamer SA. Combining public health education and disease ecology research: using citizen science to assess Chagas disease entomological risk in Texas. PLoS Neglected Trop Dis. 2015;9(12):e0004235

34. Qualtrics. 2018. p. Software

35. CDC. Chagas Disease in the U.S. (What United States Health Care Providers Need To Know About Chagas Disease) [Oline course]. 2018 [updated September 1, 2018. Available from: https:/www.cdc.gov/parasites/cme/ chagas/course1.html.

36. Team RC. R: a language and environment for statistical computing; 2013.

37. Ebner C, Gegenfurtner A. Learning and satisfaction in webinar, online, and face-to-face instruction: a meta-analysis. Front Educ. 2019;4:92.

38. LeCloux M. The development of a brief suicide screening and risk assessment training webinar for rural primary care practices. J Rural Ment Health. 2018;42(1):60

39. Wang S-K, Hsu H-Y. Use of the webinar tool (Elluminate) to support training: the effects of webinar-learning implementation from student-trainers' perspective. J Interactive Online Learning. 2008;7(3):175-94.

40. Johnson CL, Schumacher JB. Does webinar-based financial education affect knowledge and behavior? J Ext. 2016;54(1):n1.

41. Liu Q, Peng W, Zhang F, Hu R, Li Y, Yan W. The effectiveness of blended learning in health professions: systematic review and meta-analysis. J Med Internet Res. 2016;18(1):e2.

42. Choules A. The use of elearning in medical education: a review of the current situation. Postgrad Med J. 2007;83(978):212-6.

43. Rouse $D$. The effectiveness of computer-assisted instruction in teaching nursing students about congenital heart disease. Comput Nurs. 2000;18(6): 282-7.

44. Ramos-Rincón JM, Mira-Solves JJ, Ramos-Sesma V, Torrús-Tendero D, LlenasGarcía J, Navarro M. Healthcare Professionals and Students' Awareness of Chagas Disease: Design and Validation of Chagas Level of Knowledge Scale. Am J Trop MedHygiene. 2020;103(1):437-44.

\section{Publisher's Note}

Springer Nature remains neutral with regard to jurisdictional claims in published maps and institutional affiliations.

Ready to submit your research? Choose BMC and benefit from:

- fast, convenient online submission

- thorough peer review by experienced researchers in your field

- rapid publication on acceptance

- support for research data, including large and complex data types

- gold Open Access which fosters wider collaboration and increased citations

- maximum visibility for your research: over $100 \mathrm{M}$ website views per year

At $\mathrm{BMC}$, research is always in progress.

Learn more biomedcentral.com/submission 